\title{
The Role of Indigenous Conflict Resolution Mechanisms in the Pastoral Community: An Implication for Social Solidarity in Somali Region, Shineli Woreda
}

\author{
Tibebu Kefale Muluken \\ School of Psychology, Jigjiga University, Jigjiga, Ethiopia \\ Email: tibebupsyc@gmail.com
}

How to cite this paper: Muluken, T.K. (2020) The Role of Indigenous Conflict Resolution Mechanisms in the Pastoral Community: An Implication for Social Solidarity in Somali Region, Shineli Woreda. Open Access Library Journal, 7: e6122.

https://doi.org/10.4236/oalib.1106122

Received: January 30, 2020

Accepted: February 25, 2020

Published: February 28, 2020

Copyright $\odot 2020$ by author(s) and Open Access Library Inc.

This work is licensed under the Creative Commons Attribution International License (CC BY 4.0).

http://creativecommons.org/licenses/by/4.0/

\begin{abstract}
The main objective of this study was to examine the role of Indigenous conflict resolution mechanisms in the pastoral community for social solidarity in Shineli Woreda, which is found in Somali regional State. A qualitative research design was employed under which, Focus group discussion, semi-structured interview and observations were conducted and the data was analyzed qualitatively. A total of 60 informants were selected by using purposive sampling technique. The finding of this study revealed that, conflict in the pastoral community was largely caused by competition over scarce resources (water and pasture land related problems), livestock raids, and revenge traditions. Besides, informants indicated that historical and political factors, drought, land alienation for investment, and idleness amongst the youth were the other causes of conflict in the pastoral community. Moreover, almost all informants of the study were used and preferred indigenous conflict resolution mechanisms which are deep rooted in the pastoral community. Community elders, religious father, clan leaders are key players of indigenous conflict resolution mechanisms. Finally, study participants stated that the decision made by elders and social sanctions in the community plays a crucial role in managing conflict through ingenious mechanisms.
\end{abstract}

\section{Subject Areas}

Anthropology, Psychology, Sociology

\section{Keywords}

The Role of Indigenous, Conflict Resolution Mechanisms, Pastoral Community 


\section{Introduction}

The history of conflict is as old as human history and conflict is inevitable phenomenon [1]. Conflict is inevitable in any relationship. It will happen whether we like it or not. Conflict by itself is not positive or negative. However, how we manage the conflict can have positive or negative consequences in our relationships. Conflicts erupt when a society fails to carefully handle contradictions through tolerance, dialogue and reciprocal accommodation of interests [2].

Ethiopia is a country where various ethnic groups live together. Eldership has been part of Ethiopian culture which runs deep into the Ethiopian history but there are regional variations in the traditional eldership mechanisms of conflict resolutions. Besides the formal system of conflict resolution, different social groups have distinctive traditional settings and relationships, where the indigenous mechanisms could play a significant role in resolving and preventing violent conflicts in the community and society at large [3].

The root causes of conflict are unfulfilled or threatened human needs, including security, identity, dignity, recognition and justice. It is important to note that one great source of conflict is competition over scarce resources for survival. We may find ourselves in conflict when we think there are not enough resources like food, money, grazing land to sustain us [4].

Peace is the most important ingredient for smooth functioning of the community. Peace building is largely equated with the construction of a social environment that advances a sense of confidence and improves conditions of life. As conflict occurs at personal, communal, social, national and global levels, the styles of conflict resolution/management used differ largely at these different levels [5].

Conflicts in Ethiopia could easily be handled at the grass-root levels by the societies themselves without the direct intervention of the government. After all, Ethiopia is believed to be the home of more than 80 ethnic groups. They have their own distinct languages, and cultures. These various ethnic and cultural groups for so long years have developed their own unique political or administrative, economic, social and judicial systems. They had been able to sustain themselves without necessitating to have copied the Western modes of governance in mechanisms of conflict resolution [3].

Beyene [5] indicated that the high success rate of elders' interventions in conflict resolution was witnessed in spite of its revealed weaknesses than other types of third parties such as diplomats, professional mediators, and good offices from international organizations like the UN. In this connection, a large study of mediation in international conflicts between 1945 and 1990, over half (55\%) of the high-level mediation attempts were unsuccessful. Mediation can be deemed successful when it makes a considerable and positive difference to a management of a conflict and the subsequent interaction between the parties. In contrast, failure is defined as occurring when mediation has no reported impact on the disputant parties' behavior. However, as a society moves towards moderni- 
zation and civilization, the formal methods (modern legal systems) of conflict resolution become leading and the primary choice while the traditional practices hold secondary place in comparison to the formal court system.

Despite their widespread utility and implication, the problem faced with indigenous mechanisms of conflict resolution is that, they are not documented as contributive to peace. It usually arises when community solidarity is lost to violent conflict that the importance of such community virtues begins to get recognized. Moreover, modernity and civilization of the western world pushed to extremely fail to appreciate fully the contribution of indigenous conflict management and peacemaking mechanisms to the maintenance of a community and society solidarity. More specifically, this research has attempted to answer the following basic research objectives:

- Identify the perceived causes of conflict in the pastoral community.

- Assess the features and procedures of indigenous conflict resolution in the community.

- Indicate the most preferred and efficient mechanisms of conflict resolution in the community.

- Examine the strengths and drawbacks of indigenous conflict resolution systems.

\section{Literature Review}

\subsection{An Overview about Indigenous Conflict Resolution Mechanisms}

As long as people live in society or group, there are conflicts arising from differences of interests, prejudice, needs and ambitions. Therefore, the approach adopted to prevent or resolve such difference of interests determines its resolution. In other words, when a conflict happens, the crucial point should be the effective adoption of the necessary principle of the resolution. Indigenous mechanisms are grass root approaches to solve conflicts by the society [6] [7] [8].

The most important elements involving in this mechanism include the tradition of forgiveness, respect for elders because of their symbolic authority to enforce decisions and transfer of resource as compensation [9] [10] [11].

Indigenous conflict management and resolution mechanisms use local actors and traditional community-based judicial and legal decision-making mechanisms to manage and resolve conflicts within or between communities. Local mechanisms aim to resolve conflicts without resorting to state-run judicial systems, police, or other external structures [9] [12] [13].

\subsection{Strengths and Challenges of Indigenous Conflict Resolution Mechanisms}

Some of the advantages of indigenous conflict resolution, in contrast with the court litigation or formal way of conflict resolution are given as it has low cost, speed, accessibility, cultural relevance, and responsiveness to the poor people's 
concerns. According to Ethiopian Human Council [14] also revealed that indigenous conflict resolution is advantageous as the conflicting parties are active participants, raising public interest and awareness, gives rise to permanent resolution of conflict as well as it employed non-discriminatory approach on its conduct.

Indigenous conflict management and resolution mechanisms aim to resolve conflicts locally, preceding or replacing external conflict resolution and thereby reducing reliance on external structures. Indigenous mediation helps the community keep control over the outcome of the conflict. Implementing this approach does not require sophisticated party structures or expensive campaigns; it provides a low-cost, empowering means of resolving conflicts within a relatively short time frame [11] [15].

In many societies, elders have indigenous jurisdiction in facilitation, arbitration, and monitoring outcomes [1]. Indigenous conflict mediators typically possess moral status, seniority, neutrality and respect of the community; they are acceptable to all parties and demonstrate leadership capacity. Resolutions are generally accepted and respected by all concerned parties [5].

According to Hashim [15] indicated that some indigenous conflict resolution efforts may be weakened by age or gender bias for example, in cases with no women elders, some women may believe that male elders are biased against women and that this will be reflected in their decisions. Therefore, the above idea can imply that the indigenous authorities are predominantly not progressive elements of social change.

Indigenous conflict resolution processes will allow community members to pursue remedies and resolve conflicts outside of the courtroom and still within their own cultural confines. Practiced in Indigenous communities since time immemorial, they are culturally more appropriate than litigation because they are based on the customs and traditions of the group concerned. Litigating in court is normally prohibitive; with long case queues, intermittent delay in the resolution of motions or claims is quite common. More importantly, litigation with its basic rudiments of confrontation, fault-finding and judge made resolutions, coupled with its adversarial nature [16].

Assefa [1] has summarized only some of the advantages of indigenous conflict resolution mechanisms as they quickly respond to crisis in terms of time, they contribute to the reduction of regular court case loads, they contribute to saving of the public money, it also minimizes the problem in shortage of judges who work in the regular courts, and budget constraints, they are complementary to modern government structures and are not substitutes or competitors as some government officials think and worry about, They give access to many people who do not find modern system of conflict resolution comfortable, affordable or suitable to their needs, Disputants are satisfied with their operation and view their outcomes as fair.

Even though indigenous conflict resolution has its own socio-economic advantage for individuals, groups, societies and communities, it has facing many 
challenges from different directions. The main challenges that affect indigenous conflict resolution method are lack of clear legal mandates, limited financial support from different national and international governments and limited capacity for oversight of system performance can all put in danger the effectiveness of the method to improve access to justice for the society [17].

\section{Methods of the Study}

\subsection{Study Area}

This study was conducted in Sitti zone, Shineli Woreda, in Somali Regional State. It is one of the nine zones in Somali Regional State in Ethiopia. Sitti zone is bordered on the south by Dire Dawa and the Oromia Region, on the west by the Afar Region, on the north by Djibouti, on the east by Somali land, and on the southeast by Jijiga city. For this study, Shineli Woreda pastoral community members were the study population.

\subsection{Design}

The research design for this study was a qualitative approach which aimed to examine the indigenous conflict resolution mechanism in the pastoral community for social solidarity.

The justification for using a qualitative approach is that, it provides in-depth and rich information on the issue under investigation.

\subsection{Participants}

The sample for this study was selected from members of the pastoral community, under which, 60 informants were selected as sample of the study. Those informants of the study were selected to conduct interview and focus group discussion (FGD) by using purposive sampling technique. This implies that only those individuals who are believed to give enough and relevant information in the pastoral community was included.

Accordingly, informants of interview and focus group discussion (FGD) was selected on the criteria that they would have better accumulated knowledge and experiences on the issue undertaken.

\subsection{Instruments}

A mix of primary and secondary sources of data was employed. The primary data was collected through focus group discussion (FGD), semi-structured interview and observation. The secondary sources of data were official or unofficial documents pertaining to the study undertaken. Finally, the collected data was analyzed though in a qualitative way.

\section{Results and Discussion}

\subsection{Nature of Conflict in the Community}

Conflict is not a new phenomenon in the pastoral community. However, the 
nature of conflict changed from time to time at intra and inter-clan level. In the study area, competition for scarce resources (water and pasture land) and livestock raids were issues related with the nature of conflict. However, conflicts happened in the community, the conflicts are solved by indigenous way. In this regard, Informants of the study indicated that, Somali people have a strong sense of respect to the legendary indigenous rules and guidelines that descended to them from their predecessors.

When a breach of conflict or misbehavior is detected, reference is quickly made to such unwritten customary laws on the basis of the normative framework and values systems entrenched in their culture from time immemorial. One such fundamental norm is the fear of and respect for elderly personalities in the respective community. Elders are believed to have the wisdom and insightful thought accumulated over long period of time. They are considered as instrumental for the transfer of traditional knowledge and custom to successive generations.

\subsection{Major Causes of Conflict in the Pastoral Community}

Informants and focus group discussants were indicated that Conflicts among the pastoral communities are largely caused by competition over scarce resources (water and pasture land), livestock raids and revenge tradition. Beyene [5] stated that pastoralists are facing more pressure and challenges because of the loss of pasture land, and water related problems.

In addition to this, respondents were revealed that, conflicts include historical and political factors, drought, land alienation for investment, and idleness amongst the youth were the other causes of conflict in the community. The result of this study is somehow consistent with previous conducted research by [3].

Mesfin [10] revealed that exploitation of natural resources and other related environmental stresses are crucial in all phases of the conflicts, from outbreak and perpetuation of violence to undermining prospects for peace. He noted that at least $40 \%$ of the intrastate conflicts in the last sixty years are associated with natural resources (land and water problems).

According to elders of the study area, even if conflicts have been raised between intra clans, they are temporal and occasional. According to the elders' response, conflicts between clans in the last many years were mainly for access and uses of resources such as farm, grazing lands, water issues and sometimes land alienation for project. As the data obtained from interview and focus group discussion informants, the communities were characterized by competition over grazing land and water resources. Resource scarcity pertaining to grazing lands and water resources has increased levels of violent conflict and tension between local communities.

The data gained from the focus group discussion participants indicated that, there are different reasons for the existence of land conflict in the study area. From these common reasons of land conflict, many people do not have land es- 
pecially grazing land for their cattle and camel. Because of shortage of grazing land, many people get into conflict to protect his/her land to be taken by another body. Moreover, discussants also said that, inheritances, ownership of land and boarder conflict are mentionable causes of conflict in the community. The finding is relatively competent with the previous research conducted by [11].

Indigenous conflict resolution system cultivates the relationship of conflicting parties towards the future. This conflict resolution method is necessary for the re-establishment of social relationship or bringing together of the society in general and conflicting parties in particular. Indigenous conflict resolution system allows conflicting parties to work cooperatively by minimizing their gap in productive way that does not demolish their relationship [10].

Indigenous conflict resolution mechanism can provide us procedures that can resolve disagreements successfully without harming relationships. In indigenous conflict resolution process, the conflicting parties could rather help to learn information that will permit them to work more efficiently to their future life [18]. Indigenous conflict resolution can provide us procedures that can resolve disagreements successfully without harming relationships. The method used for a conflict at hand can make available a frame work to deal with predictable conflicts [19].

The data gained from focus group discussion participants revealed that local elders have playing great role in providing advice for the community to minimize local conflicts. One key Interviewee participants also said that we are always advice the conflicting parties to solve their conflict through local elders. Because the decision passed by court or formal conflict resolution systems is not good for social relationship rather it leads revenge in the community.

\subsection{The Role of Indigenous Conflict Resolution Mechanisms in the Community}

Pastoral communities have two conflict resolution options: the formal (modern) and informal (indigenous) systems. The modern system of conflict resolution is conducted in court through litigation with strict procedures. However, the informants of the study revealed that, when compared with modern institutions, the indigenous systems for prevention and resolution of conflict less complex, save time and money. In this connection, [3] asserted that indigenous conflict resolutions are time-tested and effective in handling conflict.

\subsection{Preferences of the Community towards Indigenous Conflict Resolution}

The conflict resolutions in the pastoral community by local elders and mediators may take the form of negotiation or arbitration and generally reached an agreement with reference to Somali people norms, values and traditions.

Informants clearly stated that, indigenous conflict resolution are widely used and popular in the pastoral community and have different advantages, including 
responding quickly to crisis, contributing to reduction of regular court case load, contributing to save public money or resources. Indigenous conflict resolution mechanisms give access to many people who do not find the modern system of conflict resolution comfortable, affordable, or suited to their needs, satisfy disputants with their operation and their outcomes are seen as fair. This is because these mechanisms give a chance to the parties to actively participate in handling their affairs compared to the modern legal system.

Tigist [9] asserted that traditional conflict resolution mechanisms are very helpful as they allow the community to handle their problems in their own way. She also added that, unlike the modern ones, indigenous conflict resolution mechanisms focus on reconciling feuding parties rather than punishing. In addition, Social sanctions are the central law enforcement mechanisms of indigenous conflict resolution.

Such mechanisms give emphasis for longstanding and cross cutting ties among community members while the modern legal system work according to fixed code of law and marked by corruption. As compared to modern systems of conflict resolution, traditional mechanisms of prevention and resolution of conflicts are less complex, more time saving, and give chance to parties in conflict to actively participate in solving their own problems, and handling their own affairs by their own way. On top of these, FGDs and interview participants clearly stated that the pastoral community chooses indigenous conflict resolution mechanisms as compared to the legal systems (court) for conflict arising at any level in the study area.

According to informants, going to court bears grudge, because the outcome is definitely win-lose, which spoils future social interaction in one hand. Large investment of time and money to finish the conflict cases in court result in redundant appointment that is made for further investigation, and marked by corruption.

\subsection{Procedures of Indigenous Conflict Resolution Mechanism in the Community}

In the pastoral community, there are indigenous conflicts management institutions that have existed for long periods of time and remain effective. The procedures for managing these conflicts are vital in preventing chronic violence. Almost all discussants and interview participants were explained that, 90 per cent of disputes are resolved on the first try with indigenous conflict resolution mechanisms. And the remaining 10 per cent are resolved through the state intervention although sometimes the conflict cases turn back to elders through indigenous conflict resolution. The result of this study relatively is consistent with previous study conducted by [1].

The institutions that elders developed are generally respected because elders are seen as trustworthy and knowledgeable people in the community and are believed to make rational decisions. The unwritten Xeer-customary law of the so- 
ciety is exercised by the well-experienced elders who transfer the informal rules, values and traditions from one generation to another. The elders play the role of mediating, arbitrating, managing and resolving the conflict in the community [10].

According to informants, the process of indigenous conflict resolution based on consultation and open discussion between the disputant parties. Mediation is carried out by a person of high social standing, commonly elders, religious fathers, clan leaders who use their social legitimacy and facilitative skill. In accordance with Somali custom, elders are the key actors in the process of conflict resolution.

Discussants of FGDs were stated that, In the event of any violent conflict, there are steps followed in the resolution process. In its initial intervention, elders' council consisting of 10 to 12 members advises the conflicting parties just to cool down their temper and conflict. After listening to conflicting parties, the council of elders invites one of their members to repeat the main causes of the conflict. These steps lead to the final decision on the case in which the council requests the conflicting parties to leave the place for some time in order to judge the evidence gathered secretly and finally disclose the decision. If the accused group accepts the decision given by elders, the conflict will be settled. But, if he does not accept it, he can appeal up to 12 times for the case to be reconsidered.

Interview participants indicated that offence against another member of the community is usually resolved upon the payment of compensation both in livestock and cash. In this regard, an entire clan or sub-clan is said to be responsible for acrime committed by one or some of its members. The money and livestock to be paid in compensation is thus usually contributed by clan members regardless of their place of residence. For instance, if a man from a particular clan kills a member of the other clan, it is not an individual that defends his case, rather, it is any other two members of his clan that would appear at the indigenous conflict resolution system.

Moreover, amount of blood money for the compensation will be decided (100 cattle for unintentional killing and 150 cattle for intentional killing). Out of 100 cattlels, the family of the deceased will have 15 and the remaining 85 will be shared among other members of the clan. Informants also said that, different numbers of cattels are given for blood money compensation for different injuries depending on its severity. Besides, to recover and maintain smooth relationship between the two actors of the conflict, the injured is taken by the family of the injurer to take care of him by feeding, attending to him until his recovery.

\subsection{Actors of Indigenous Conflict Resolution Mechanisms in the Community}

Informants indicated that, Conflict in has been resolved through different traditional conflict resolution mechanisms. In the study area, community elders, religious father, clan leader are key players of indigenous conflict resolution in the 
community.

Furthermore, focus group discussant stated that, sometimes the role that women play within the customary systems in resolving conflict and sustaining peace were mentionable. In this connection, there is a saying "women are considered as ambassador in resolving inter-clan conflict in the community".

\subsection{Strength and Challenges of Indigenous Conflict Resolution Mechanisms}

Respondents indicated that Indigenous mechanism of conflict resolution consumes lower cost and the process takes greater speed, the reason for this is solving conflicts through this mechanism normally requires the permission, and commitment of the parties involved in the process. Implementing this approach does not require sophisticated party structures or expensive campaigns; it provides a low-cost and empowering means of resolving conflicts within a relatively short time frame. The process is less challenging than formal conflict resolution system and so reduces the likely hood of win or loss mentality and provides a frame work for the future dispute between the parties. As opposed to formal conflict resolution system, indigenous conflict resolution process is faster, cheaper and less formalized in the process of resolution [20].

Informants said that, the most common complaint about formal conflict resolution systems or courts is the prolonged nature of their procedures and the associated belief that taking a very long period of time. In addition, to hear the case over a number of sessions and to bring witnesses or other evidence were mentionable in related with the court system.

The data obtained from focus group discussion and interview also assured that using indigenous conflict resolution mechanism has many advantages in relation with saving of money and time. It takes short period of time to solve conflicts and disputants can solve their conflict in their local area. It decreases the cost and time involved in solving conflict like material cost, transportation cost, time and other costs. But using formal or court system takes a very long period of time to solve a single case and leads to economic crises like; court charge, filling cost, and expenditure for lawyers, and other costs. Therefore, indigenous conflict resolution system is more advantageous or merit full in terms of saving money and time.

The challenges of indigenous conflict resolution method are lack of clear legal mandates, limited financial support from different national and international governments and limited capacity for oversight of system performance can all put in danger the effectiveness of the method to improve access to justice for the society, specially these issues are visible in developing countries [21].

The focus group participants said that sometimes the government provides training but when the government tried to give training for local elders, the process of selecting the participants was unfair. The Kebelle administrator selects his close friends and others who have kinship with him sent to the training area 
due to political manipulation. This situation created that locally accepted leaders could not develop their capacity.

The other challenge raised by group discussion participants was sometimes the decision of local elders does not accept as a binding rule by the government. This means after decision passed by local elders on conflict parties, the government continued to punish the disputants by neglecting the decision of the elders.

Therefore, the result indicated that the government does not provide the right support to consolidate indigenous conflict resolution mechanism with the formal court system in the community.

\section{Summary and Conclusions}

\subsection{Summary}

The major goal of this study was to examine the role of indigenous conflict resolution mechanisms in the pastoral community for social solidarity in Somali region, Shineli Woreda. To achieve this study, a qualitative research design was employed to explore the role of indigenous conflicts resolution mechanism in the community and its implication for social solidarity.

The data were collected through interview, focus group discussion, and observation. A total of 60 informants were selected purposefully for this study. The finding results revealed that competition over natural resources (pasture land and water related problems), livestock raids and revenge traditions were the main cause of conflict in the pastoral community.

Elders, religious fathers and clan leaders were the key players of indigenous conflict resolution mechanisms. Furthermore, the pastoral communities preferred indigenous conflict resolution than modern system (courts) due to the various reasons: First, it is flexible as compared to formal legal systems that are perceived as full of strict procedures. Second, it plays a fundamental role to maintain social harmony and solidarity in the pastoral communities.

\subsection{Conclusions}

Majority of the informants indicated that competition over scarce resources (water and pasture land related issues), livestock raids and revenge traditions were the main cause of conflict in the community. Besides, informants also revealed that historical and political factors, drought, land alienation for investment, and idleness amongst the youth were the other causes of conflict in the pastoral community.

Informants were indicated that conflict resolution via local conflict mediators is preferable than using formal system or court system in the study area. There are different reasons that forced the residents to use indigenous conflict resolution mechanism. First, the costs of indigenous conflict resolution system like material cost, transportation cost, time and other costs are low. Second, the process of indigenous conflict resolution system takes greater speed.

Finally, indigenous conflict resolution system is very important means of con- 
flict resolution by increasing social harmony, addressing common problems of the community and increasing support of each other and tolerance. In order to promote sustainable peace in the pastoral community, indigenous conflict resolution mechanisms should be integrated and work jointly with the modern systems of conflict resolution.

\subsection{Recommendations}

Based on the result, the following recommendations were made and forwarded:

- It would be better if the government gives due attention to the values and social assets of indigenous conflict resolution mechanisms like the modern legal system.

- It would be better if the government provides training on indigenous conflict management system in the community.

- Initiate indigenous conflict handling strategies and formulate structures for policy implementation.

- It would be better if the media support indigenous conflict resolution mechanism for peace building strategies.

\section{Conflicts of Interest}

The author declares no conflicts of interest regarding the publication of this paper.

\section{References}

[1] Assefa, A. (2005) Traditional Conflict Resolution and Challenges in Ethiopia: The Experience of Oromo in Ethiopia. A Report on Ethiopia Workshop, Addis Ababa.

[2] Hussien, J. (2014) Ethnic Conflict as a Global Political Problem: Review of Conceptual and Theoretical Perspectives. Organization for Social Science Research in Eastern and Southern Africa, OSSREA, Ethiopia.

[3] Assefa, A. (2001) Indigenous Mechanisms for the Prevention and Resolution of Conflicts: The Experience of Oromo in Ethiopia. A Report on Ethiopia Workshop, Addis Ababa.

[4] Aden, M. (2005) An Assessment of the Socio-Economic Impacts of Conflict on Pastoral and Semi-Pastoral Economies in Kenya and Uganda. Nairobi, Practical action in East Africa.

[5] Beyene, F. (2007) The Role of Customary Institutions in Managing Conflict on Grazing Lands: The Case of Meiso District, Eastern Ethiopia. ICAR Discussion Paper, No. 7. Humboldt University of Berlin, Berlin.

[6] Chirot, D.E. and Seligman, M.E. (2001) Ethnopolitical Warfare: Causes, Consequences, and Possible Solutions. American Psychological Association, New York, xvii-379. https://doi.org/10.1037/10396-000

[7] Hewstone, M. and Greenland, K. (2000) Intergroup Conflict. International Journal of Psychology, 35, 136-144. https://doi.org/10.1080/002075900399439

[8] Fisher, M. (2010) Sources of Conflict and Methods of Conflict Resolution. https://pdfs.semanticscholar.org/c79d/9b7849528d3fa2170d33b6382f7da2b77a11.pd $\underline{\mathrm{f}}$ 
[9] Gashaw, T. (2003) Indigenous Conflict Resolution Mechanisms in Ethiopia: The First National Conference on Federalism, Conflict and Peace Building.

[10] Tadesse, B., Tesfaye, Y. and Beyene, F. (2010) Women in Conflict and Indigenous Conflict Resolution among the Issa and Gurgura Clans of Somali in Eastern Ethiopia. African Journal on Conflict Resolution, 10. https://doi.org/10.4314/ajcr.v10i1.59308

[11] Brock-Utne, B. (2001) Indigenous Conflict Resolution in Africa. In: A Draft Presented to Week-End Seminar on Indigenous Solutions to Conflicts, the University of Oslo, Institute of Educational Research, Oslo, 23-24.

[12] Tesfay, Y. and Tafere, K. (2004) Indigenous Rangeland Resources and Conflict Management by the North Afar Pastoral Groups in Ethiopia. Drylands Coordination Group Report, Ethiopia.

[13] Ho-Won, J. (2007) Institute for Conflict Analysis and Resolution. Ashgate Publishing Ltd., Aldershot, Hampshire.

[14] Ethiopian Human Rights Council-EHRCO (2003) Conflict between Dizzi and Surma Nationalities, a Problem that Requires Immediate (Urgent) Solution. 29th Special Report, Addis Ababa.

[15] Hashim, T. (2003) Conflict-Management Structures and Intervention under the Ethiopian Constitutions. First National Conference on Federalism, Conflict and Peace Building, Ministry of Federal Affairs and German Technical Cooperation, United Printers, Addis Ababa.

[16] Mesfin, G. (2006) Ethnicity and Ethnic Conflict in Post Federal Ethiopia: A Case in Mai'so District Conflict between Oromos and Somalis. Research Papers Ethnic and Religious Conflicts in the Southern Hemisphere. Stadtschlaining, European University Center for Peace Studies.

[17] Yohannes, K. and Zerihun, A. (2005) Addressing Pastoralist Conflict in Ethiopia: The Case of the Kuraz and Hamer Sub-Districts of South Omo Zone. Africa Peace Forum, Ethiopian Pastoralist Research and Development Association, Interafrica Group, Saferworld.

[18] Mekonnen, T. (2003) Conflict of Frontiers between the Oromia and Somali: The Case Study of Moyale Woreda. First National Conference on Federalism, Conflict and Peace Building. Ministry of Federal Affairs and German Technical Cooperation, Addis Ababa.

[19] Befekadu, Z. and Diribssa, A. (2005) Inter-State Ethnic Conflict: Theory and Implication of Ethiopia. In: The OSSREA Proceedings of the 2nd National Workshop of the Ethiopian Chapter, October 2005.

[20] Eshetu, T. and Getu, M. (2000) Implementation and Practices of Traditional Conflict Resolution. Workshop Paper, Addis Ababa.

[21] Best, K. (2000) Working with Conflict. McMillan Inc., London. 